Thirteen Cases of Chorea following Scarlet Fever.

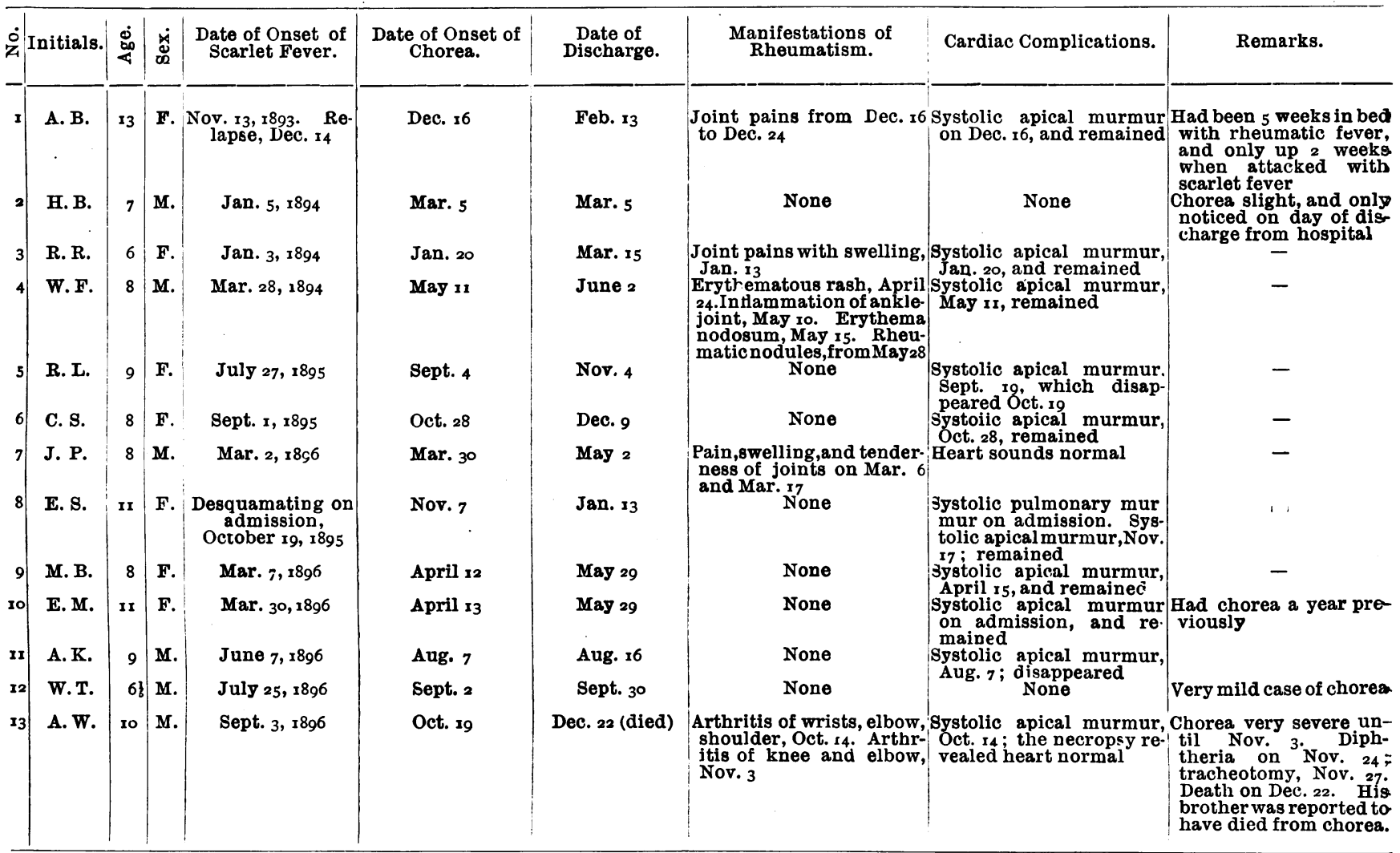

the nature of the joint affections which go with chorea (" the choreic arthropathies") and those which go with scarlet fever, though both are classed in statistics under the expansile term "rheumatism."

\section{Cardiac Implication.}

The proportion of heart affection in first attacks of chorea is given as 30 per cent. ${ }^{6}$ It will be seen that 7 out of the 13 developed murmurs which remained till the date of discharge. If we leave out of consideration cases (2) and (10) as evidently not valid, this gives 7 in 11 , or over 60 per cent., which is in harmony with the statement in the Collective Investigation report that " scarlet fever would seem to predispose to the occurrence of heart affection in chorea." The average interval between the scarlet fever onset and that of the chorea was over 35 days.

REFERENCES.

1 Manual of Infectious Diseases. ${ }^{2}$ System of Medicine (Allbutt), vol. ii. 3 BRITISH MEDICAL JouRNAL, 1887 . vol. i. 4 Chorea (published 1896) 5 See Report of Statistical Committee of Metropolitan Asylums Board, 1896, p. 156. 6 Collective Investigation Committee's Report; Osler On Chorea.

\section{A CASE OF RAYNAUD'S DISEASE. Bx ALBERT MOUILLOT, M.D. Harrogate.}

Miss N. H. consulted me in March, when she told me that she was 15 years of age, and up to November, 1896, had enjoyed fair health, though always a sufferer from cold hands and feet. This coldness of the extremities became worse, and in November her left hand began to swell, became painful, and looked quite black. The hand got extremely tender-so tender, indeed, that she could not bear even to have her nails cut. This swelling, pain, and tenderness rendered the hand so useless that she was unable to pick anything up with it. This state of things continued in spite of care until her visit to Harrogate in March, but, except that menstruation had ceased, there was no sign of impairment of the general health.

When I saw Miss $H$. her condition was very striking. The hands and feet were deadly cold, as also was the tip of the nose ; the ears were quite warm. The extremities were of $a$. bluish-black colour when cold and of a deep red when warm. The left hand was greatly swollen and the fingers were kept. fully extended; she was quite unable to flex them herself, and any attempt to do so caused extreme pain. The coldness and black colour extended half way up the left forearm. The condition of the nails was very peculiar; they were snowwhite in colour, and very long owing to the pain on cutting them. Miss $H$. said that sometimes her hands and feet got. hot, and when they did the pain was much worse. There was no albuminuria nor any history of hæmoglobinuria.

Miss $H$. was in this condition when she accompanied me to the meeting of the Leeds Medico-Chirurgical Society on March igth, at which she was carefully examined by many of the leading leeds physicians, who concurred in the diagnosis, though one physician suggested that the case came nearer to. the disease known as erythromelalgia than to what is usually called Raynaud's disease. It seems safer, however, to retain the more general name.

It appeared to me that the only chance of improving a condition like that described was to keep the patient in an equable temperature and endeavour to improve the nutrition of the body by frequent feeding with nutritious food, at the same time treating the local and general conditions by careful and skilful massage. The Weir-Mitchell treatment, the great value of which I have so often proved, met all the indications, and accordingly I sent $\mathrm{my}$ patient to the Victoria Nursing. Home, Harrogate, on March 24th.

The improvement under this treatment was uninterrupted. At first the manipulations had to be very gentle, but gradually more and more could be borne, so that at the end of seven weeks my patient left the home practically well. All 
the extremities were warm and of good colour; the useless left hand had become so well that Miss $H$. could play scales on the piano with it; the white nails had become pink, and menstruation had twice taken place. A fortnight after all treatment had ceased I introduced my patient to the members attending the meeting of the Yorkshire Branch of the British Medical Association.

The foregoing brief notes of a very interesting case suggest that the line separating what is commonly known as a "bad circulation" from the more severe forms of angio-spastic and angio-paralytic disease is a narrow one. One frequently sees cases which are habitually blue and cold without there being any other symptom of ill-health. These patients generally tell one that they are suffering from that very common disease (with the laity), a weak heart, though as a rule there is no indication of weakness in that organ. May not many of these cases be mild examples of the disease usually called by Raynaud's name?

The excellent result of treatment in this case would also suggest that in similar conditions the Weir-Mitchell treatment in its entirety should be tried, as whatever theory one may have as to the exact pathology of such cases, the rest cure, combining as it does good feeding, bodily and mental rest, warmth and massage, meets all the symptomatic indications.

\section{THE PREVALENCE OF THROAT AFFECTIONS AMONG FEMALE ELEMENTARY SCHOOL TEACHERS IN MANCHESTER.}

By EUGENE S. YONGE, M.D.EDIN.

Assistant Medical Officer, Manchester Hospital for Consumption and Diseases of the Throat.

OBSERVATION of the fact that large numbers of female teachers present themselves at hospital on account of various pathological conditions of the pharynx or larynx led me to believe that throat disease in certain forms was common in these individuals. With the object of clearing up this question and of ascertaining what causative factors were in operation to produce the state of things referred to, I selected at haphazard Ioo female teachers who were pursuing their occupation in elementary schools. I was enabled to carry out this investigation through the courtesy of the Manchester School Board and of the authorities of various voluntary schools.

The teachers were drawn from eight Board and eight Voluntary schools; the institutions were visited, and the general surroundings of the female instructors noted. After interviewing the total number of teachers, 70 of them were submitted to laryngeal and pharyngeal examination ; the remaining 30 were not so treated, either on account of the brevity of their tutorial experience, or because they were obviously in such a state of health as to render the presence of any throat affection unlikely; they have therefore, in calculating percentages, been considered normal. The following table shows the lesions discovered in the laryngeal and pharyngeal cavities of the 70 teachers examined.

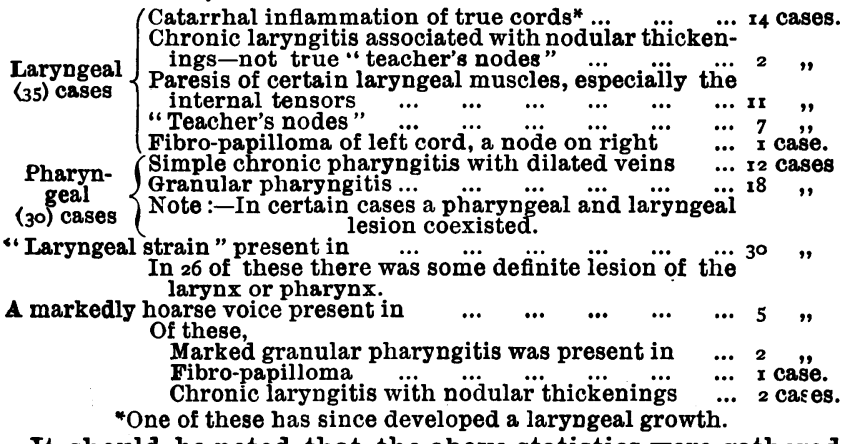

It should be noted that the above statistics were gathered from a number of individuals who were presumably healthy, and an examination of the surroundings of these persons revealed a collection of causes acting with more or less potency to produce the various pathological conditions enumerated. My own experience leads me to believe that the most powerful factor in producing vocal defects in teachers is the practice of conducting more than one "noisy" or "oral" lesson in the same room at the same time ; for, in addition to being forced to convey the sound of her own voice to a somewhat inattentive audience, the individual who is conducting a class has to endeavour to drown the sounds emanating from other teachers and pupils close at hand. In a few schools I noticed that at least three "noisy" lessons were going on at the same time, and it was a matter of some difficulty to make oneself heard by a teacher at a few yards' distance. The two following hospital cases appear to demonstrate the deleterious effect on the vocal organs of "noisy" lessons simultaneously held :

CASE I.-Miss B. had been teaching for twelve years. She had been hoarse for one month before she presented herself at the Throat Department of the Manchester Consumption Hospital. when she was discovered to be suffering from laryngeal nodes. She had taught for several years ago she was drafted into a large and usually noisy chamber, and by the end of three months had developed nodes.

Ca three months had developed nodes. CASE II.-Miss T. had been teaching for six years. She began to be hoarse two months before coming to the hospital, and the majority of her singing voice quickly became lost. The patient had taught for several years in a small quiet school without sufrering in any degree from her phot. Eventually she became one of the teaching staff in a poor and populous district or san inester. Sometimes as many as three "noisy" losuon we Theol possessed a classroom but patients The street, not a main thorough two months "teacher's nodes had developed, as proved by laryngeal

In the foregoing cases there are, I think, sufficient grounds for assuming that laryngeal disease was not present before the hoarseness and other vocal disabilities commenced, and these seem to have been determined by a specific change in the teachers' surroundings. Other influences tending to the production of throat disease in teachers appeared to be the noise of traffic in the streets; the employment of boards for flooring instead of wooden bricks (which appreciably deaden the sound produced when classes are moving about); the presence of suspended particles of chalk in the air (Ellis ${ }^{1}$ ) and the conduction of classes in large lofty rooms with bad acoustic properties.

In addition to the above, other injurious agents, such as classes which are too large (that is, exceeding 40 to 60 pupils); ignorance of the elements of voice production (a want of knowledge which frequently leads to unnecessary shouting); the commencing of duties at too early an age, 13 to 16 , when, as Milligan ${ }^{2}$ has pointed out, the vocal organs are not in a position to stand any undue strain, and when the first great tax is being put upon the female economy; all these have been suggested as probable factors in the production of throat disease in teachers, or in the predisposition thereto.

The following is a brief analysis of the cases collected, and the conclusions derived therefrom:

I. Forty-five per cent. of the total number of teachers were suffering from some definite lesion of the larynx or pharynx - the term "definite lesion". excluding mere temporary congestion of those structures-leading to the supposition that throat disease in certain forms is common among female teachers in elementary schools.

2. The commonest condition was some laryngeal anomaly (35 cases) ; pharyngeal lesions were present in 30 cases.

3. The laryngeal lesions occurred in the following order of frequency-catarrhal inflammation, 16 cases ; paresis of certain laryngeal muscles, II cases; " teacher's nodes," 7 cases ; and fibro-papilloma, 1 case.

4. A definite history of "laryngeal strain," a tired aching feeling usually referred to the region of the larynx, was present in 30 cases, and as all but 4 of these showed some lesion of the larynx or pharynx, it appears to be a symptom of some importance.

5. A markedly hoarse voice was noted in 5 cases. In 2 of these marked granular pharyngitis alone was present ; in there was a fibro-papilloma, and in 2 irregular congested and thickened cords.

6. By far the most potent factor concerned in the production of throat affections appeared to be the absence or paucity of class rooms, leading to the necessity of holding two or more "noisy" or " oral" lessons simultaneously in the same room. This conclusion was arrived at $(a)$ from the preponder- 